\title{
Research on Strategies of Improving the Foreign-related Service Capacity of Starred-hotels' Staff in Wuhan
}

\author{
Shao Xiao-hui ${ }^{1, a}$, \\ ${ }^{1}$ School of Management, Wuhan Industry and Business University, Wuhan 430065, China \\ a shaoxiaohui@wtbu.edu.cn
}

Keywords: Wuhan; Starred-hotels; Foreign-related Service Capacity; Improving strategies

\begin{abstract}
With the establishment of Wuhan 'the thirteenth five-year plan', Wuhan tries to realize the transformation from the first-class domestic tourism destination into the internationally renowned waterfront tourism and leisure destination, this upgrading goal puts forward higher requirements of starred- hotels' staff in service skills and language abilities. This paper analyzed on Wuhan starred-hotel staff questionnaire and found out that Foreign-related Service Capacity of Wuhan star hotel staff was limited by their English and service skills, and it tries to put forward some effective improving strategies from three aspects: Foreign-related service capacity's training, the staff's self management and hotel management aspects.
\end{abstract}

\section{武汉星级酒店从业人员涉外服务能力提升策略研究}

\author{
邵晓晖 $1, a$ \\ 1武汉工商学院管理学院, 湖北, 武汉, 中国 \\ a shaoxiaohui@wtbu.edu.cn
}

关键词：武汉；星级酒店；英语服务能力，提升策略

中文摘要. 随着武汉 “十三五” 规划的确立,城市目标定位于实现从全国旅游目的地向全国一 流、国际知名的滨水旅游休闲特色目的地的转型升级。此发展目标对星级酒店从业人员的涉 外服务能力提出了更高的要求。本文通过对武汉星级酒店从业人员英语服务能力进行问卷调 查分析、了解员工英语服务能力现状, 探索性提出酒店培训、员工、以及酒店管理多层面的 可行的提升策略。

\section{1. 引言}

“十二五” 期间, 武汉市旅游接待游客数量从 0.89 亿人次增加至 2.07 亿人次, 旅游总收入 从753.73亿元增加至 2197.41 亿元, 两项指标年均增长速度均超过 $15 \%$, 分居副省级城市第一、 二位。全球排名前十的酒店集团已有 9 家进驻武汉, 全市五星级酒店数量已达 14 家, 按五星级 标准建设的酒店16家，四星级以上酒店共计 60 家，数量居同类城市前列。

“十三五”期间，武汉市旅游的发展将从全球、全国和区域等不同层面寻找定位,最终实 现武汉旅游从全国旅游目的地向全国一流、国际知名的滨水旅游休闲特色目的地的转型升级。 国际化发展目标对旅游接待业是机遇也是挑战, 同时星级酒店作为接待服务重要组成部分, 其从业人员的涉外服务能力取到决定性的作用。如何提升酒店从业人员涉外服务能力成为酒 
店业的需求, 本文以武汉星级酒店代表为调研对象进行问卷调查, 旨在找出代表武汉涉外服 务能力水平的星级酒店从业人员涉外服务能力水平现状, 能分析现存主要问题, 找到提升途 径。

\section{2. 武汉星级酒店从业人员英语服务能力现状调查}

\section{1 问卷设计与发放}

为了对武汉星级酒店从业人员英语服务能力和培训情况进行了解, 在参考相关文献资料 的前提下, 制定了本文的调查问卷。在武汉市内各星级酒店发放了相关问卷102份, 其中有效 问卷102份，问卷回收有效率为 $100 \%$ 。调查对象覆盖了酒店的前厅部、餐饮部、客房部、康 乐部、安保部、财务部、工程部、人力资源部和销售部共 9 个部门, 酒店内部所有部门基本都 有涉及。

问卷设计内容主要分为四部分内容, 一是对被调查对象基本信息的了解; 二是通过对被 调查对象工作级别、所在部门和英语基础的了解, 可以推断出影响从业人员英语水平的因素; 第三部分是了解从业人员对英语服务这一技能所持的态度; 第四部分是对提升从业人员英语 服务能力对策的调查，从而设计出更合适的提升策略。

\section{2 问卷分析}

\subsection{1.调查对象基本情况分析}

从性别上来看，接受调查的人员中女性居多，占总被调查人员的 $70.59 \%$ 。男女性别比为 3:7。反映出武汉市酒店从业者女性员工的数量高于男性员工, 这也是酒店服务行业普遍存在 的一个特点。

人员结构中, 实习生要占到大多数为 $52.94 \%$, 其余 $47.06 \%$ 则是酒店的正式员工, 这也 是受调查者受教育程度本科及本科以上学历的员工占大多数高达 $66.67 \%$, 大专为 $24.51 \%$, 其 余 $8.82 \%$ 的员工则是高中及中专以下学历的原因, 即: 武汉市酒店中员工学历普遍较高, 而这 一结果偏高的原因是因为酒店员工大多为实习生而非正式员工, 酒店高素质服务群体的稳定 性偏少。

从受调查者工作年限的调查结果来看。一年以下的员工超过了一半为 $59.8 \%$, 其次是工作 四年及以上的员工占 $19.6 \%$, 而工作 1 年至 2 年、 2 年至 3 年、 3 年至 4 年的员工所占比例分别为 $11.8 \% ， 2.0 \%$ 和 $6.9 \%$ 。我们可以了解到武汉酒店大多数员工从事酒店行业的时间不是很长, 这也与基层员工岗位变动大、流失率高、实习生在所调查员工中所占比重过高有关。

被调查人员的中, 基层员工接受此次调查的比重高达 $66.7 \%$, 其次是经理级及以上的则占 $14.7 \%$, 主管级占到了 $10.8 \%$, 而领班级占 $7.8 \%$ 。基层员工是服务一线的, 是本次调研的主体 部分。该群体积极配合认真如实的填写了自己在酒店工作生活的切实感受。

调查问卷反映出接受调查的人员岗位覆盖安保部、财务部、餐饮部、工程部、康乐部、 客房部、前厅部、人力资源部、销售部。其中前厅部即含前台接待、礼宾部、大堂、行政楼 层、总机等有 46 人占此次调查的 $45.1 \%$, 都是处于接待住店客人的第一线, 能否给住店客人留 下良好的初印象，以及难忘的最终印象，在很大程度上都取决于前厅部的服务质量。

2.2.2.武汉星级酒店从业人员英语服务能力现状分析

从下面表1中数据可知, 当前酒店员工有一定英语基础的员工占多数, 一点也不会的员工 占 $4.9 \%$, 这部分员工可能是英语基础较差, 工作环境中没有机会加以锻炼口语。在调查中能 听懂简单口语内容和能简单阅读的员工比例分别为 $34.3 \%$ 和 $14.7 \%$, 这说明这些员工是有一定 英语基础, 只是缺乏系统的酒店服务英语的专业教学培训。英语水平基本能应对本职工作的 员工占 $39.2 \%$, 加之能听懂简单口语和看懂简单英文的员工, 有英语基础且能快速进入英语 培训的员工还是占大多数。在受调查的员工中能非常流利且没有交流障碍的员工比例仅为 $6.9 \%$, 由此不难看出, 涉外服务能力还有待提升。 
表1 武汉星级酒店员工英语水平调查表

\begin{tabular}{|c|c|c|c|c|}
\hline \multicolumn{2}{|c|}{} & 频率 & 百分比 & 有效百分比 \\
\hline 有效 & 非常流利, 没有交流障碍 & 7 & 6.9 & 6.9 \\
\cline { 2 - 5 } & 基本能应付工作 & 40 & 39.2 & 39.2 \\
\cline { 2 - 5 } & 能简单阅读 & 15 & 14.7 & 14.7 \\
\cline { 2 - 5 } & 能听懂简单内容、口语尚可 & 35 & 34.3 & 34.3 \\
\cline { 2 - 5 } & 一点都不会 & 5 & 4.9 & 4.9 \\
\cline { 2 - 5 } & 合计 & 102 & 100.0 & 100.0 \\
\hline
\end{tabular}

从问卷调查得知, 星级酒店员工的英语服务能力普遍较低, 少部分员工的英语口语水平 基本可以应付本职工作, 但多数员工仅能听懂部分简单内容, 用英语提供优质服务很难做到, 这是酒店对客服务的满意度提升不了的关键因素, 这样就制约了酒店国际化发展的进程。酒 店从业人员在工作期间, 工作任务重, 缺乏时间和精力去参加培训学习英语。其次是因为酒 店没有建立培训体系、员工没有积极地心态去接受培训, 导致很多酒店员工英语水平停滞不 前。各星级酒店经常接到外国客人的投诉, 很大一部分原因是因为员工英语服务能力的限制, 这一因素制约了酒店业的国际化发展。为了改变这一局面, 必须加强建立完善的英语培训机 制，从而提升武汉星级酒店从业人员英语服务能力。

\section{3. 武汉星级酒店从业人员的英语服务能力提升对策}

\section{1 酒店方面应建立有效的培训体系}

英语服务能力培训是改进酒店服务质量的关键，它不仅能体现出酒店的管理水平，也能 提升酒店在同行间的竞争力。首先, 就是需要一个有实际经验的专业培训团队, 它必须对酒 店背景、岗位需求以及酒店员工的英语水平有深刻了解, 其次结合了解信息, 制定出提升英 语服务能力培训的大纲和内容。

\subsection{1. 加强酒店员工跨文化沟通能力的培养}

星级酒店员工在为客人提供服务时, 酒店形象的重要体现就是语言的素养。英语培训教 学不可能脱离文化而独立存在, 因此, 培训教师在传授语言知识的同时, 应扩大员工的知识 面, 开拓他们的视野, 让他们了解不同国家的历史和文化, 在此过程中积累文化知识和提升 自身素质。酒店员工不仅要掌握在实际情景中需要正确表达的内容, 更重要的是可以将国家 文化、语音语调和所要表达的内容结合起来, 达到与客人交流的目的, 运用英文提供优质的 服务, 使其有宾至如归的感受。任何一种语言都是文化的载体, 文化是语言学习的手段和目 的, 民族丰厚的文化内涵和社会文化特征都蕴藏在其中。文化必然会存在差异, 文化影响语 言的应用, 因此酒店对于员工英语服务能力的培训不仅要注重语言本身, 更要结合国外文化 来开展培训, 让员工将良好的礼仪面貌展现给外国客人, 给客人留下良好的印象。所以, 酒 店员工应掌握一定的跨文化知识, 这对提升自身的英语服务能力是很有必要的。

3.1.2. 结合部门岗位需求进行分层、切实可行的培训计划及目标

由于所处岗位不同, 以及员工原本英语水平的不一, 所以需要制定不同的英语培训目标 和计划。首先，通过测试把员工的英语水平进行分类，根据不同类别制定出不同的英语培训 计划; 其次, 必须对不同部门的员工应当具备的英语能力水平进行准确的衡量。通常而言, 前厅部所接触外宾的机率最高, 因而要将前厅部员工英语水平的培训要作为重中之重。其次 就是餐厅服务员, 主要就是点餐用语, 具有专业性, 所以要针对专业方面进行准确培训。而 其他部门, 英语水平要求就相对较低, 但也需要做日常简单对话的练习。对于酒店管理人员 也需要针对不同岗位需要对其涉外服务能力进行需求明确, 培训有针对性。

3.1.3. 科学合理的安排培训实间、内容 
英语的学习是需要时间的保障的, 但酒店工作工作强度大、相对繁忙、空余时间少, 再 之每个岗位的员工要分成多个班次, 所以很难保证有统一的时候可以安排教学工作。根据酒 店工作的实际情况, 应合理地安排出培训方案, 科学地设计培训方法, 有效的提高培训效果。

在英语入学基础学习阶段, 可将各部门的员工集中起来做统一培训, 使员工都能有一个 良好的学习英语的基础, 再根据不同岗位及划分的酒店英语课程的进度进行授课。可采取线 上分散学习、线下集中场景模拟学习、岗位直接实践指导等环节。如表2所示:

3.1.4. 严格要求英语培训讲师的选拔

酒店英语不同一般的学校教学式英语, 它有着自己显著的特点。在酒店英语培训教师的 选拔中, 一定要足够重视, 要充分了解酒店英语的特殊性, 能够把酒店英语的针对性和灵活 性合理的结合起来, 采用科学的教学方式让员工得以理解和接受。目前, 酒店的英语培训教 师无非是内部英语较好的员工或者从高校请来的专业教师, 这两种方法都有弊端, 内部员工 不能够系统的讲解内容, 而高校专业教师又缺乏实践经验。所以, 两者结合起来的专门人才 才是酒店真正需要的培训师。

\subsection{5. 创新有效的教学模式}

培训师在教学的时候, 要有创新意识和良好的教育理念和技巧, 突破常规的教学方式, 采用灵活的 “走动式课堂” , 将员工带到各个岗位工作的环境中, 根据具体的工作场景进行 有针对性的培训, 这种随时随地培训的方式可以让员工充分的融入到工作环境中, 发散思维, 大大提高培训效率, 充分利用零碎的时间来解决针对性的问题, 这样合理安排培训内容, 也 增强了英语培训的效果。实录情景模拟、诊断提升更能激发员工的学习兴趣, 调动员工的学 习积极性, 而且员工与情景之间发生的各种信息交流, 可以极大地开发人的潜力, 使员工在 考虑任何问题时都能够从实际需要出发, 全面提高员工的个人能力。改变传统的教学方式, 让员工学习他们迫切需要的语言及技能, 加速了对新知识的理解进程, 从而全方位提高英语 综合运用能力。

\section{2 从业人员应培养有效的自我学习状态}

在酒店中，英语的运用范围很广，从前厅、餐饮到客房，但凡涉及酒店工作，都会用到 英语。酒店英语的学习就是充分了解酒店行业背景、加强酒店情境英语的应用能力, 从而提 高酒店的英语服务水平和质量。

首先, 员工要了解酒店背景文化知识, 学习专业化知识和理论基础, 然后是掌握在特定 环境下的语言技能, 如一些专业词汇、委婉语、语言形式及应当注意使用的语音、语调等, 最后将二者结合起来, 应用到实际的日常工作中去, 让外宾也能享受到舒适优质的服务, 对 酒店产生宾至如归的美好印象。

\section{3 酒店建立相关管理制度促进员工涉外服务能力提升}

\subsection{1. 采用激励机制让员工转变英语学习态度}

由于受酒店工作性质的影响, 工作繁忙业余时间较紧, 对英语不敢兴趣, 加上英语基础 差, 所以酒店从业人员对英语学习的愿望并不强烈。为了转变现状, 酒店方可以对员工采取 些激励措施。酒店培训师和管理层员工相互配合, 强调英语培训与管理职能的结合, 突出英 语服务的重要性, 不仅可以提升服务水平, 增加自己的业绩, 还可以展现本酒店的形象。酒 店可建立科学合理的英语培训考核标准, 对于在培训中表现突出的员工通过相应的激励机制 进行奖励, 激发员工学习英语的主动性和积极性, 逐步让员工发自内心的学习、沟通, 从根 本上改变学习态度。

3.3.2. 酒店管理方面可建立行业内的人才交流的培养机制酒店管理方可设置不同英语等级的 岗位津贴, 提升员工改善涉外服务能力的愿望并形成晋升机制, 明确各管理岗位的英语服务 能力标准。 
其次，可通过个人申请、选派旅游企业推荐、接受省旅游局的协调、调控的方式，每年 选派优秀旅游从业人员作为精英赴国内、外对外程度高涉外服务优的企业导师所在单位的相 关岗位进行研修，使他们能够及时跟踪了解行业动态和发展趋势，提高涉外服务水平。

\section{4. 结束语}

旅游业的迅速发展使得我国酒店业如雨后春笋般蓬勃发展起来，要想在酒店业内脱颖而 出, 就需要向国际化迈进, 提升酒店从业人员的英语服务能力成为是否能够成功的关键。国 际化的发展趋势不断深入旅游接待业, 那么对于酒店人才的需求标准也会随之提高, 目前通 过培训、激发员工自我提升是主要途径。星级酒店还可以在员工招聘中对其英语服务技能和 管理技能进行考量, 从引进人才环节来直接提升星级酒店的涉外英语服务能力水平的提升。

\section{致谢}

本文为2015年湖北省旅游研究课题项目《湖北旅游从业人员涉外服务能力提升策略研究》 (2015006), 2017年度湖北省教育厅科学研究计划指导性项目《湖北省研学旅游主题开发研 究》（B2017316）的阶段性成果之一。

\section{References}

[1] Zhou Qi, Research on the countermeasure of Star hotel staff English service ability based on the present situation's analysis, Overseas English, vol.5, pp. 107-111, 2012.

[2] Feng Yana, Research on strategies of Star- hotel staff's English training in Zhengzhou City, Co-operative Economy \& Science, vol.5, pp. 28-29, 2014.

[3] Zhu Dongbi, Research on strategies of Star- hotel staff's English service ability, Journal of Hubei Correspondence University, vol.10, pp. 136-137, 2013.

[4] Wei You xi, Simple Analysis on the Gap Between Our English curriculum and the Modern International Hotel Requirements, HuaZhang, vol. 2, pp. 190, 2014.

[5] Xu wei and Dai Chunmei, Analysis and Btrategies based on the Research of the Hotel Industry Employee's English Ability Demands , Vocational Education Forum, vol.14, pp. 131-132, 2015.

[6] Yu hongyan and Wu ping, Research on Ascension Paths of Business Hotel Interns' Foreign Service Ability, Tourism Overview, vol. 5, pp. 211-212, 2018. 